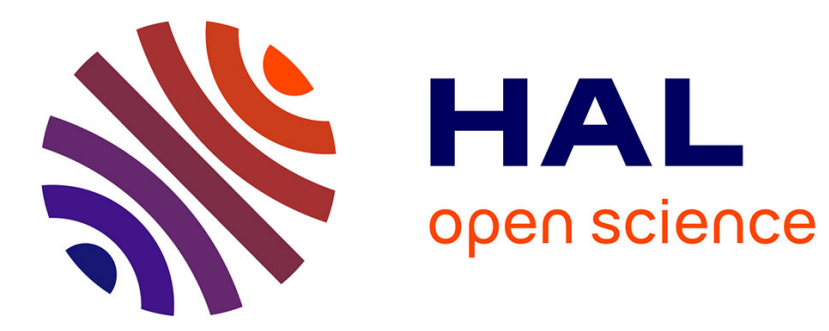

\title{
Photoactivated surface grafting from PVDF surfaces
}

Thomas Berthelot, Xuan Tuan Le, Pascale Jégou, Pascal Viel, Bruno Boizot, Cécile Baudin, Serge Palacin

\section{To cite this version:}

Thomas Berthelot, Xuan Tuan Le, Pascale Jégou, Pascal Viel, Bruno Boizot, et al.. Photoactivated surface grafting from PVDF surfaces. Applied Surface Science, 2011, 257, pp.9473. 10.1016/j.apsusc.2011.06.039 . hal-00616622

\section{HAL Id: hal-00616622}

https://hal-polytechnique.archives-ouvertes.fr/hal-00616622

Submitted on 23 Aug 2011

HAL is a multi-disciplinary open access archive for the deposit and dissemination of scientific research documents, whether they are published or not. The documents may come from teaching and research institutions in France or abroad, or from public or private research centers.
L'archive ouverte pluridisciplinaire HAL, est destinée au dépôt et à la diffusion de documents scientifiques de niveau recherche, publiés ou non, émanant des établissements d'enseignement et de recherche français ou étrangers, des laboratoires publics ou privés. 


\author{
Photoactivated surface grafting from PVDF surfaces \\ Thomas Berthelot ${ }^{\mathrm{b}, *}$, Xuan Tuan Le ${ }^{\mathrm{b}}$, Pascale Jégou ${ }^{\mathrm{b}}$, Pascal Viel ${ }^{\mathrm{b}}$, Bruno Boizot ${ }^{\mathrm{a}}$, \\ Cécile Baudin ${ }^{b}$, Serge Palacin ${ }^{b}$ \\ ${ }^{a}$ Laboratory of Irradiated Solids UMR 7642 CEA/CNRS/Ecole Polytechnique, CEA-DSM/IRAMIS LSI, Ecole \\ Polytechnique, F-91128, Palaiseau Cedex, France \\ ${ }^{b}$ Chemistry of Surfaces and Interfaces, CEA Saclay, DSM/IRAMIS/SPCSI, F-91191, Gif-sur-Yvette Cedex, France
}

\begin{abstract}
Economic and easy methods to tune surface properties of polymers as Poly(vinylidene fluoride) (PVDF) without altering bulk properties are of major interest for different applications as biotechnological devices, medical implant device... UV irradiation appears as one of the simplest, easy and safe method to modify surface properties. In the case of self-initiated grafting, it is generally assumed that the pretreatment of the PVDF surface with UV irradiation can yield alkyl and peroxy radicals originating from breaking bonds and capable of initiating the subsequent surface grafting polymerizations. Surprisingly, the present work shows that it is possible to obtain polymer grafting using low energetic UV-A irradiation (3.1-3.9 eV) without breaking PVDF bonds. An EPR study has been performed in order to investigate the nature of involved species. The ability of the activated PVDF surface to graft different kinds of hydrophilic monomers using the initiated surface polymerization method has been tested and discussed on the basis of ATR FT-IR, XPS and NMR HRMAS result.
\end{abstract}

\title{
1. Introduction
}

Poly(vinylidene fluoride) (PVDF) is a semi-crystalline and well known polymer which presents excellent chemical and thermal stabilities and even compatibility with biological substances including blood, food, etc. [1]. The main disadvantage of PVDF is its non-reactivity towards chemical compounds, which induces using complicated and expensive surface modifications methods as plasma, irradiation (heavy ions, electrons, _-radiations), corona discharge, flame, ozone treatment, ... [2] in order to improve its use for biotechnology as drug delivery system or 
biosensors. It is thus interesting to find a simple and cheap surface modification method which provides on one hand, fluoropolymer devices with different surface properties (hydrophilicity, biocompatibility. . .) and on the other hand, keeps unaffected the bulk properties as flexibility, piezoelectric or ferroelectric properties for example [2-4]. In the 1990s, the surface modification of fluoropolymer films was shown to be induced by V-UV irradiation (100-200 nm) treatments in oxidative or reductive atmospheres [5-7]. V-UV photons energy $(6.2-12.4 \mathrm{eV})$ is sufficient to break $\mathrm{C} \mathrm{F}$ and/or $\mathrm{C} \mathrm{H}$ bonds at the fluoropolymer surface resulting in radical production which can eventually react with organic or gas molecules [6]. More recent publications [8,9] proposed various procedures for preparing polymer brushes from PVDF surfaces by UV-B irradiation (4.17 $\mathrm{eV}$ ) and subsequent air exposure to create peroxide and hydroperoxide species which induce direct surface polymerization. Surprisingly, we recently found that low-energy UV-A irradiation (3.1-3.9 eV) can also induce polymer grafting by surface initiated polymerization, although its energy is not enough to break $\mathrm{CF}$ or $\mathrm{CH}$ bonds. In order to investigate the actual nature of the active species generated during UV-A irradiation of PVDF, we performed Electron Paramagnetic Resonance (EPR) studies which are presented here. Reactivity of these UV-A-activated surfaces towards different acrylate monomers is also reported and discussed on the basis of ATR FT-IR, XPS and NMR HRMAS results.

\section{Experimental}

\subsection{Materials}

Hydrophobic poly(vinylidene fluoride) films (PVDF $\beta, 9 \mu$ m thick, Solvay SA or Piezotech SA) were Soxhlet extracted in toluene and dried at $50^{\circ} \mathrm{C}$ under vacuum. The PVDF films were sliced into rectangular strips of size about $4 \mathrm{~cm} \times 1.5 \mathrm{~cm}$ and then stored in nitrogen atmosphere. The percentage of $\beta$ phase was obtained by the method described in [10] and was 67\% for PVDF film from Solvay SA and 64\% for PVDF from Piezotech SA. Acrylic acid (Fluka) and 2-hydroxyethyl methacrylate (Aldrich) were distilled under reduced pressure and stored in a nitrogen atmosphere at $4{ }^{\circ} \mathrm{C}$ before use. Water was MilliQ-grade. $\mathrm{NaBH} 4$, $\mathrm{LiAlH} 4$, acetonitrile and tetrahydrofuran (THF) were purchased from Sigma-Aldrich and used as received.

\subsection{UV-A irradiation}


To overcome the high absorbance of Pyrex in the spectral range of UV-A, quartz tubes were used during the irradiation step. After adding the PVDF film, the quartz tube was closed with silicon rubber stopper and degassed with nitrogen for $30 \mathrm{~min}$. The UV-A source was located at $4 \mathrm{~cm}$ from the polymer film. The PVDF films were irradiated at room temperature for $15-60 \mathrm{~min}$. The UV-A light source (200 W) was a system (Omnicure Serie 2000) equipped with a high pressure mercury lamp possessing an emission spectrum spanning the 320-500 nm range and a bandpass filter. This UV system provides an irradiance level of $30 \mathrm{~W} \mathrm{~cm}-2$ with maxima of light emission at 369, 407 and $438 \mathrm{~nm}$ (Fig. 1). The collected light was analyzed by a SHAMROCK spectrograph $(\mathrm{F}=303 \mathrm{~mm} ; 150$ lines/mm grating and a 400 _m slit) combined with an ANDOR Istar Intensified Charge-Coupled Device (ICCD).

\subsection{Polymerization on the UV irradiated films}

The exact conditions for the surface polymerization on the UV-irradiated PVDF films are gathered in Table 1. Before the polymerization, the monomer and the solvent (if any) were deaerated separately by bubbling N2 gas for $1 \mathrm{~h}$. They were then introduced into a degassed tube containing the UV-A irradiated film for designated time (15-60 min). The sealed tube was put into a thermo-stated bath at $60^{\circ} \mathrm{C}$ (see Table 1 for the duration). After polymerization, the film was submitted to ultrasonic treatment in a good solvent of the corresponding monomer for 15 min. A Soxhlet extraction was then performed in water for $12 \mathrm{~h}$ and the resulting film was dried under high vacuum. The polymerization and work-up conditions were summarized in Table 1.

\subsection{Carbonyl reduction of PVDF surface}

Surface PVDF films were submitted to two different protocols in order to reduce carbonyl group. Protocol A: NaBH4 (100 mg, $2 \mathrm{mmol}$ ) were dissolved in $20 \mathrm{~mL}$ of MilliQ Water and then PVDF films were disposed in this solution. After $3 \mathrm{~h}$ at $40^{\circ} \mathrm{C}, \mathrm{PVDF}$ films were rinsed with $0.1 \mathrm{~N} \mathrm{HCl}$ solution and with ethanol. Resulting films were flushed with nitrogen gas and stocked under vacuum. 
Protocol B: $30 \mathrm{~mL}$ of THF were cooled at $-30{ }^{\circ} \mathrm{C}$ with a liquid Nitrogen/Acetonitrile bath. Afterwards, $100 \mathrm{mg}$ of LiAlH4 $(2.6 \mathrm{mmol})$ were added and PVDF films were disposed in the resulting solution for $4 \mathrm{~h}$. Finally, resulting PVDF films were rinsed with ethanol, flushed with nitrogen gas and stocked under vacuum.

PVDF films obtained by these two protocols were analyzed by ATR FTIR and were submitted to the same UV irradiation protocol and polymerization step described in the Sections 2.2 and 2.3.

\subsection{Characterizations}

\subsubsection{EPR characterization}

The EPR experiments were carried out at room temperature on a $\mathrm{X}$ band $(v=9.420 \mathrm{GHz}) \mathrm{EMX}$ Bruker EPR spectrometer using a $100 \mathrm{kHz}$ field modulation, 3 gauss $(\mathrm{G})$ of amplitude modulation and an applied microwave power of $1 \mathrm{~mW}$. The spectra were obtained by sweeping the static magnetic field (from 3275 to $3375 \mathrm{G}$ ) and by recording the first derivative of the absorption spectrum. In order to compare the quantity of radical defects created by UV-A irradiation on different experiments, all spectra were normalized to a sample weight of $100 \mathrm{mg}$ and to a receiver

gain of $10^{4}$. A maximum error of $10 \%$ has been considered by taking into account the background noise, the experimental errors on sample weight and on the sample position into the spectrometer cavity. In situ irradiations of PVDF were performed in a quartz tube under nitrogen atmosphere on EPR spectrometer cavity. Afterward, the PVDF samples were flushed or not with air for 10 min and then kept under nitrogen atmosphere during EPR data recording.

\subsubsection{Infrared spectroscopy measurements}

FTIR spectra of the polymer films were carried out with a Nicolet Magna-IRTM 750 spectrometer equipped with a deuterated triglycine sulphate detector (DTGS). The spectra were recorded in the Attenuated Total Reflectance mode (ATR) using a diamondcrystal with single reflection. Spectra were collected by cumulating 128 or 256 scans at a resolution of $2 \mathrm{~cm}-1$ using $\mathrm{H} 2 \mathrm{O}$ and $\mathrm{CO} 2$ correction.

\subsubsection{X-ray photoelectron spectroscopy (XPS)}


Photoemission studies were performed with a Kratos Axis-Ultra DLD spectrometer, using the monochromatized $\mathrm{Al}-\mathrm{K} \alpha$ line at $1486.6 \mathrm{eV}$ with a power source equal to $150 \mathrm{~W}$. Fixed analyzer pass energy of $20 \mathrm{eV}$ was used for all core level scans. The photoelectron take-off angle was 90。 with respect to the sample plane, which provides an integrated sampling depth of approximately $15 \mathrm{~nm}$ for XPS. In order to avoid charge effects, a neutralization system based on electrons focalized onto the analysis area was used. All the PVDF samples and a gold reference were mounted together onto a single glass substrate to get a homogeneous floating potential and the neutralizer system was calibrated to over-compensate the charge effects. Then, all spectra were

shifted in order to get the $\mathrm{Au}{ }^{4} \mathrm{f}_{7 / 2}$ gold reference sample at $83.70 \mathrm{eV}$. The analyzed surface was $700 \mu \mathrm{m} \times 300 \mu \mathrm{m}$. Percentages of oxidized defects on pristine commercial PVDF (Solvay or Piezotech SA) were calculated from the peak areas of elements $\mathrm{C}, \mathrm{F}$ and $\mathrm{O}$ from the survey spectra. The areas were corrected by the Scofield factors corresponding to each element.

\subsubsection{H NMR HRMAS spectroscopy}

All experiments were performed with a Bruker Avance 500 spectrometer equipped with a triple resonance $\left({ }^{1} \mathrm{H}^{13} \mathrm{C}^{32} \mathrm{P}\right)$ HRMAS probe head. NMR rotors were standard $\mathrm{ZrO}_{2} 4 \mathrm{~mm}$ rotors with $50 \mu \mathrm{L}$ filling. Spinning frequency was $5 \mathrm{kHz}$. Deuterated water was purchased from Eurisotop (France). The samples were lyophilized in $\mathrm{D}_{2} \mathrm{O}$ before their introduction into the rotor. The solvent and the homopolymer were suppressed by diffusion filter used in classical NMR. A PVDF-g-PAA (grafting level $28 \mathrm{wt} \%$ ) obtained by electron irradiation and acrylic acid radiografting [11] was used as reference.

\subsubsection{Water angle contact}

The contact angle $\theta$ of distilled water at film surface was measured with Appollo Instrument's AC01 Goniometer (Compiègne, France).

\section{Results and discussions}

\subsection{UV Irradiation of PVDF surface and surface-initiated free radical polymerization}


As reported in the literature [12-14], PVDF surface modification is generally performed with different acrylate monomers owing to many advantageous properties of the corresponding polymers: hydrophilicity, biocompatibility, antifouling or antibacterial properties... Surface modification of PVDF by light is currently performed with high-energy photons which can break polymer bonds to form radical moieties that eventually react with oxidative or reductive atmosphere to generate activated surface for polymerization [5-9].

In this work, we use an alternative process to surface modification of PVDF. It is well known that PVDF surface presents some chemical defects as $\mathrm{C}$ C double bonds and oxygen-containing groups [15-18]. The presence of the oxidized defects of PVDF surface is confirmed by the XPS and FT-IR spectra of both commercial pristine PVDF films. The weak peak at $533 \mathrm{eV}$ on the survey spectrum of pristine PVDF (Fig. 2), attributable to O 1s signal, confirms that the PVDF surface is partially oxidized. Likewise, the C 1s core level spectrum of pristine PVDF, which is usually curve-fitted with three peak components at the binding energies (BEs) of $285.72 \mathrm{eV}$ for $\mathrm{CH}$ neutral species, $286.99 \mathrm{eV}$ for $\mathrm{CH}_{2}$ species and $291.46 \mathrm{eV}$ for $\mathrm{CF}_{2}$ species, actually presents a broadened additional peak component at $288.53 \mathrm{eV}$ (Fig. 2). This peak component can be assigned to the overlapping contributions of $\mathrm{CF}_{2}-\mathrm{CO}-\mathrm{CF}_{2}$ and $\mathrm{CH}_{2}-\mathrm{CO}-\mathrm{CF}_{2}$ species and represents a surface oxidation of circa $0.6 \%$. In order to have an idea of the oxidized defects distribution, seven different spectra were recorded on different locations on each commercial PVDF sample (Table 2).

Table 2 gives the atomic percentages of oxygen derived from above XPS analyses performed on various locations of both commercial PVDF samples. Average percentages of oxidized defects on the surface of commercial PVDF films are 0.5\% (Piezotech SA) and 0.62\% (Solvay SA).

The ATR FT-IR spectra of pristine PVDF film (Fig. 3) corroborate the presence of these oxidized defects as well. In pristine PVDF samples, the presence of two weak bands at $1724 \mathrm{~cm}^{-1}$ and $1761 \mathrm{~cm}^{-1}$ generally attributed to carbonyl bands confirms the partial oxidation of the PVDF surface [15-18].

Our goal is to take benefit of those oxidized defects already present in the pristine PVDF films to build a functionalization process of the PVDF surface. In fact, many photochemical reactions in organic synthesis involve oxygen-containing groups or carbonyl functions [19]. We thus decided to use low-energy photons (UV-A: 320-500 nm) for two reasons: (i) to avoid polymer bond breaking that is observed when higher-energy photons are shined on PVDF and (ii) to activate 
those "spontaneous" chemical defects on PVDF surface for subsequent polymerization. To the best of our knowledge, no one ever used these defects to graft polymer by photoactivation.

Hence, acrylate grafting on PVDF films was performed according to the reaction shown schematically in Fig. 4. PVDF film was first subjected to UV-A irradiation (320-500 nm) in nitrogen and then used to initiate the surface-polymerization of monomers as acrylic acid (AA) or 2-hydroxymethyl methacrylate (HEMA) (Table 1). All grafting experiments were compared to control experiments which were done with the same experimental set-up and the same workup procedure on pristine PVDF films.

The experimental results show that the UV-A irradiated PVDF surface initiates the polymerization of AA and HEMA.

Fig. 5 displays ATR FT-IR spectra of the carbonyl absorption region (2000-1500 cm-1) of grafted films, together with the control experiments. Both grafted PVDF films exhibit a carbonyl band at $1717 \mathrm{~cm}^{-1}$ (AA) and $1724 \mathrm{~cm}^{-1}$ (HEMA) respectively, which is consistent with the expected grafted polymers PAA and PHEMA.

Water contact angles $\theta$ were measured (Table 3 ) and confirmed the increase of the hydrophilicity of the PVDF surface after grafting PAA and PHEMA.

More attention was paid to PVDF films modified with poly(acrylic) acid (PAA) because of its easier post-functionalization to produce, for example, biotechnological devices (sensors, drug delivery systems...) via chemical engineering. As FTIR ATR results, the XPS data confirm PAA grafting on PVDF surface. Two new component peaks appear in the C 1s core level spectrum of PAA modified films (Fig. 6) with respect to pristine PVDF (Fig. 2). These additional component peaks at BEs of $285.17 \mathrm{eV}$ and $289.24 \mathrm{eV}$ are attributed to the hydrocarbon backbone and the $\mathrm{O}$ $\mathrm{C} \mathrm{O}$ species of the grafted PAA polymer chains, respectively. These results are supported by the appearance of a high $\mathrm{O}$ 1s signal in the survey scan spectrum of the PAA modified film (Fig. 6).

Fig. 7 shows the variation of surface grafting yield as a function of the polymerization time with a constant AA monomer concentration and with a constant UV-A irradiation time: the higher the polymerization time, the higher the quantity of grafted PAA.

High resolution magic angle spinning (HRMAS) NMR spectroscopy has proven to be a groundbreaking technique to study molecules bound to solid supports like resins or polymers [20]. In a previous work, the rate of PAA radiografting in the bulk of PVDF was derived from NMR spectra recorded in an appropriate solvent of PVDF: DMF-d7, which allowed the full 
dispersion of the PVDF-g-PAA gel [21]. Here, a different approach was used. All HRMAS NMR experiments were recorded in deuterium oxide in order to swell only the grafted PAA chains without solvating at all the PVDF film. By this process, only the PAA chains which present some mobility, i.e. located at a long distance of the PVDF surface, actually produce ${ }^{1} \mathrm{H}$ NMR signals. ${ }^{1}$ H NMR shifts of grafted PAA chains obtained after UV-A irradiation (Fig. 8b) were compared to those obtained after electron irradiation [11] (Fig. 8a).

\subsection{EPR study}

The EPR spectra of PVDF after UV-A irradiation and relaxation times are presented in Fig. 9. After 15 and 60 min of UV-A irradiation (Fig. 9a and b) a complex and weak EPR signal appears whereas the pristine PVDF sample (Fig. 9d) produces only a very small signal just above the noise. Two different EPR lines, at $\mathrm{g}=2.0048$ and $\mathrm{g}=2.0006$ are observed (Fig. 9a and $\mathrm{b}$ ) and could be associated to hole and electron centers, respectively. Those observed EPR signals are clearly different from the ones observed on PVDF films after irradiation with high-energy light, which were assigned to alkyl and per-oxy radicals resulting from $\mathrm{CH}$ and $\mathrm{CF}$ bond breaking $[3,4$, $8,22-25]$. In order to demonstrate the nature of these novels activated species, UV-A-irradiated films were exposed to air for $10 \mathrm{~min}$ and EPR spectra were again recorded. No significant change in the EPR spectra was observed between samples exposed or not to oxygen, whatever the irradiation time. This result confirms that active species formed by UV-A irradiation are not alkyl or per-oxy radicals since (i) they do not react with air, contrary to the latter [8]; (ii) they are unlikely to result from polymer bond breaking because the energy brought by UV-A irradiation $(\mathrm{E}=3.88 \mathrm{eV}$ at $320 \mathrm{~nm}$ ) is not enough to break the $\mathrm{C}-\mathrm{H}, \mathrm{C}-\mathrm{C}$ and $\mathrm{C}-\mathrm{F}$ bonds found in PVDF ([26] and Table 4). We actually found that the EPR signals observed on Fig. 9 exhibit a similar slow decrease in intensity either left in the presence of oxygen or not (Fig. 10). In both cases, the EPR signals completely disappear after 4.5 days (Fig. 9d). As described in Fig. 11, monitoring the EPR signal as a function of irradiation time clearly exhibits saturation after 15 min of irradiation. This result confirms that UV-A irradiation does not break bonds at the PVDF surface but only activates latent species already present on pristine PVDF surface. In fact, the rapid saturation behavior is not compatible with bond breaking as described in [8], which has no reason 
to saturate, but more likely with a process involving a finite number of pre-existent defects on the PVDF surface.

A plausible mechanism can be based on the presence of latent diamagnetic species in surface oxidation defects of PVDF, activated by UV-A irradiation. As presented in our experimental data, the number of chemical defects, i.e. oxidation of PVDF surface, is a finite quantity which involves a limited number of processes that saturate with the dose. Furthermore no polymerization occurs after the EPR signal decrease of the irradiated film. This hypothesis fits with the irradiated PVDF EPR signal and its evolution.

In order to validate this hypothesis, we have submitted the surface of PVDF films to reducing media as $\mathrm{NaBH} 4$ aqueous solution at $40{ }^{\circ} \mathrm{C}$ or a mixture of $\mathrm{LiAlH}_{4} / \mathrm{THF}$ at $-30{ }^{\circ} \mathrm{C}$. Resulting reduced PVDF films were analyzed by ATR FTIR. Aqueous solution of $\mathrm{NaBH}_{4}$ has not reduced the carbonyl groups as depicted in Fig. 12. This can be explained by an unfavorable wettability of PVDF films due to its high hydrophobic character. To overcome this drawback, the reduction of carbonyl group was performed in a mixture of $\mathrm{LiAlH}_{4} / \mathrm{THF}$ at $-30 \circ \mathrm{C}$ for $4 \mathrm{~h}$ and no carbonyl vibrational band was detected on ATR FTIR spectrum (Fig. 13). The resulting reduced PVDF films were subjected to the same UV irradiation and polymerization procedures than pristine PVDF films. Fig. 14 shows that no polymerization occurred with reduced PVDF films.

\section{Conclusions}

In this work, we have described a new synthetic way to graft acrylate and methacrylate polymers on PVDF films. This approach is based on a photochemical activation of pre-existing defects on the PVDF surface by low-energy photons (320-500 nm). EPR studies highlight that UV-A irradiation activate latent species on the PVDF surface resulting from chemical defects (i.e. oxidation) but do not break polymer bonds. To the best of our knowledge, this work demonstrates, for the first time, the ability to use pre-existing defects in PVDF films to directly initiate polymerization. UV-A irradiation represents a very easy, economic and effective method to covalently attach hydrophilic polymers on PVDF films in order to produce PVDF-based devices with tunable properties.

\section{References}


[1] N. Betz, J. Begue, M. Goncalves, K. Gionnet, G. Déléris, A. Le Moel, Functionalisation of PAA radiation grafted PVDF, Nucl. Instrum. Methods Phys. Res., Sect. B 208 (2003) 434-441.

[2] E.T. Kang, Y. Zhang, Surface modification of fluoropolymers via molecular design, Adv. Mater. 12 (2000) 1481-1494.

[3] J. Deng, L. Wang, L. Liu, W. Yang, Developments and new applications of UVinduced surface graft polymerizations, Prog. Polym. Sci. 34 (2009) 156-193.

[4] D. He, H. Susanto, M. Ulbricht, Photo-irradiation for preparation, modification and stimulation of polymeric membranes, Prog. Polym. Sci. 34 (2009) 62-98.

[5] J. Heitz, V. Svorcik, L. Bacakova, K. Rockova, E. Ratajova, T. Gumpenberger, D. Bauerle, B. Dvorankova, H. Kahr, I. Graz, C. Romanin, Cell adhesion on polytetrafluoroethylene modified by UV-irradiation in an ammonia atmosphere, J. Biomed. Mater. Res. 67A (2003) 130-137.

[6] V. Svorcik, K. Rockova, E. Ratajova, J. Heitz, N. Huber, D. Bauerle, L. Bacakova, B. Dvorankova, V. Hnatowicz, Cell proliferation on UV-excimer lamp modified and grafted polytetrafluoroethylene, Nucl. Instrum. Methods Phys. Res., Sect. B 217 (2004) 307-313.

[7] V.N. Vasilets, I. Hirata, H. Iwata, Y. Ikada, Photolysis of a fluorinated polymer film by vacuum ultraviolet radiation, J. Polym. Sci., Part A: Polym. Chem. 36 (1998) 2215-2222.

[8] Q. Deng, Y. Chen, W. Sun, Preparation of polymer brushes from poly(vinylidene fluoride) surfaces by UV irradiation pretreatment, Surf. Rev. Lett. 14 (2007) 23-30.

[9] Y.W. Chen, Q. Deng, J.C. Xiao, H.R. Nie, L.C. Wu, W.H. Zhou, B.W. Huang, Controlled grafting from poly(vinylidene fluoride) microfiltration membranes via reverse atom transfer radical polymerization and antifouling properties, Polymer 48 (2007) 7604-7613.

[10] B. Mohammadi, A.A. Yousefi, S.M. Bellah, Effect of tensile strain rate and elongation on crystalline structure and piezoelectric properties of PVDF thin films, Polym. Test. 26 (2007) 4250.

[11] M.C. Clochard, J. Bègue, A. Lafon, D. Caldemaison, C. Bittencourt, J.-J. Pireaux, N. Betz, Tailoring bulk and surface grafting of poy(acrylic acid) in electron irradiated PVDF, Polymer 45 (2004) 8683-8694.

[12] F. Liu, C.H. Du, B.K. Zhu, Y.Y. Xu, Surface immobilisation of polymer brushes onto porous poly(vinylidene fluoride) membrane by electron beam to improve the hydrophilicity and fouling resistance, Polymer 48 (2007) 2910-2918.

[13] M. Ulbricht, Advanced functional polymer membranes, Polymer 47 (2006) 2217-2262. 
[14] K.M. McGinty, W.J. Brittain, Hydrophilic surface modification of poly(vinyl chloride) film and tubing using physisorbed free radical grafting technique, Polymer 49 (2008) 4350-4357.

[15] G. Socrates, Infrared Characteristic Group Frequencies, John Wiley \& Sons, Chichester, UK, 1980.

[16] N. Betz, A. Lemoel, J.P. Duraud, E. Balanzat, C. Darnez, Grafting of polystyrene in poly(vinylidene fluoride) films by means of energetic heavy-ions, Macromolecules 25 (1992) 213-219.

[17] N. Betz, A. Le Moël, E. Balanzat, J.M. Ramillon, J. Lamotte, J.P. Gallas, G. Jaskierowicz, A FIIR study of PVDF irradiated by means of swift heavy ions, J. Polym. Sci., Part B: Polym. Phys. 32 (1994) 1493-1502.

[18] D. Flosch, H.-D. Lehmann, R. Reichl, O. Inacker, W. Göpel, Surface analysis of poly(vinylidene difluoride) membranes, J. Membr. Sci. 70 (1992) 53-63.

[19] A. Albini, M. Fagnoni, Handbook of Synthetic Chemistry, WILEY-VCH Verlag GmbH \& Co. KGaA, Weinheim, 2010.

[20] C. Sizun, J. Raya, A. Intasiri, A. Boos, K. Elbayed, Investigation of the surfactants in CTAB-templated mesoporous silica by 1H HRMAS NMR, Microporous Mesoporous Mater. 66 (2003) 27-36.

[21] M.C. Clochard, O. Cuscito, T. Berthelot, N. Betz, C. Bittencourt, J.-J. Pireaux, M. Gonc, alves, K. Gionnet, G. Déléris, Surface specific peptide immobilization on radiografted polymers as potential screening assays for antiangiogenic immunotherapy, React. Funct. Polym. 68 (2008) $77-90$.

[22] C. Aymes-Chodur, S. Esnouf, A. Le Moel, ESR studies in _-irradiated and PSradiationgrafted poly(vinylidene fluoride), J. Polym. Sci., Part B: Polym. Phys. 39 (2001) 1437-1448.

[23] N. Betz, E. Petersohn, A. Le Moël, Free radical in swift heavy ion irradiated fluoropolymers: an electron spin resonance study, Radiat. Phys. Chem. 47 (1996) 411-414.

[24] N. Betz, E. Petersohn, A. Le Moël, Swift heavy ions effects in fluoropolymers: radicals and crosslinking, Nucl. Instrum. Methods Phys. Res., Sect. B 116 (1996) 207-211.

[25] B. Hilczer, Dielectric response of polymer relaxors, J. Mater. Sci. 41 (2006) 117-127.

[26] E. Katan, M. Narkis, A. Siegmann, The effect of some fluoropolymers' structures on their response to UV irradiation, J. Appl. Polym. Sci. 70 (1998) 1471-1481. 
Table 1

Polymerization and cleaning-up conditions of PVDF surface grafting with different acrylic monomers.

\begin{tabular}{lll}
\hline Monomer & Polymerization conditions & Cleaning-up \\
\hline $\begin{array}{l}\text { Acrylic acid-AA } \\
\text { 2-hydroymethyl methacrylate-HEMA }\end{array}$ & pure, $60^{\circ} \mathrm{C}, 6 \mathrm{~h}$ & $\mathrm{U}^{3} \mathrm{~S}^{3}$ in basic aqueous medium then Soxhlet extraction with water \\
U.S. $^{3}$ in ethanol/water $50 / 50$ then Soxhlet extraction with water
\end{tabular}

a U.S.: Ultrasonic treatment (power consumption: $560 \mathrm{~W}$, ultrasonic frequency $35 \mathrm{kHz}$ ). 
Table 2

Average percents of oxidation defect on both commercial $\beta$ PVDF film.

\begin{tabular}{|c|c|c|c|c|c|c|c|c|}
\hline & Element & $\begin{array}{l}1 \\
\text { atx }\end{array}$ & $\begin{array}{l}2 \\
\text { atx }\end{array}$ & $\begin{array}{l}3 \\
\text { atx }\end{array}$ & $\begin{array}{l}4 \\
\text { ats }\end{array}$ & $\begin{array}{l}5 \\
\text { att8 }\end{array}$ & $\begin{array}{l}6 \\
\text { at8 }\end{array}$ & $\begin{array}{l}7 \\
\text { ats }\end{array}$ \\
\hline$\beta$ PVDF film from & $01 \mathrm{~s}$ & 0.7 & 0.7 & 0.6 & 0.6 & 0.5 & 0.6 & 0.7 \\
\hline Solvay SA & $\begin{array}{l}\text { F 1s } \\
\text { C 1s }\end{array}$ & $\begin{array}{l}47.4 \\
52.0\end{array}$ & $\begin{array}{l}47.6 \\
51.7\end{array}$ & $\begin{array}{l}47.7 \\
51.7\end{array}$ & $\begin{array}{l}47.9 \\
51.4\end{array}$ & $\begin{array}{l}48.4 \\
51.0\end{array}$ & $\begin{array}{l}49.2 \\
50.3\end{array}$ & $\begin{array}{l}48.9 \\
50.4\end{array}$ \\
\hline$\beta$ PVDF film from & 015 & 0.5 & 0.6 & 0.4 & 0.6 & 0.5 & 0.4 & 0.4 \\
\hline Piezotech SA & F 15 & 47.1 & 47.9 & 47.8 & 46.5 & 48.3 & 48.6 & 47.1 \\
\hline & C 1s & 52.3 & 51.5 & 51.7 & 53.0 & 51.2 & 51.0 & 52.5 \\
\hline
\end{tabular}


Table 3

Monomers used for surface initiated free radical polymerization on UV activated PVDF surfaces.

\begin{tabular}{llll}
\hline & PVDF $\beta$ & PVDF-PAA & PVDF-PHEMA \\
\hline Water angle contact $\theta$ & $85.81 \pm 3.02$ & $74.20 \pm 0.58$ & $72.47 \pm 3.17$ \\
\hline
\end{tabular}


Table 4

Values of $\mathrm{C}-\mathrm{H}, \mathrm{C} \rightarrow \mathrm{F}$ and different $\mathrm{C}-\mathrm{C}$ bonds energies extracted from [18]

\begin{tabular}{ll}
\hline Structures & Bond energy (eV) \\
\hline $\mathrm{C}-\mathrm{H}$ & $4.22-4.37$ \\
$\mathrm{C}-\mathrm{F}$ & 4.42 \\
$\mathrm{H}-\mathrm{CH}_{2} \mathrm{CF}_{3}$ & 4.62 \\
$\mathrm{H}_{3} \mathrm{C}-\mathrm{CF}_{3}$ & 4.29 \\
\hline
\end{tabular}




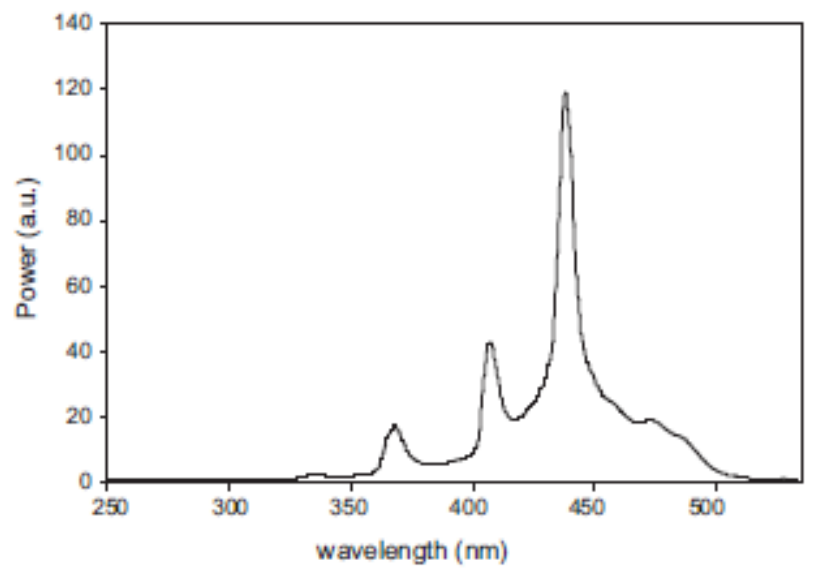

Fig. 1. Emission spectrum of the UV lamp. 

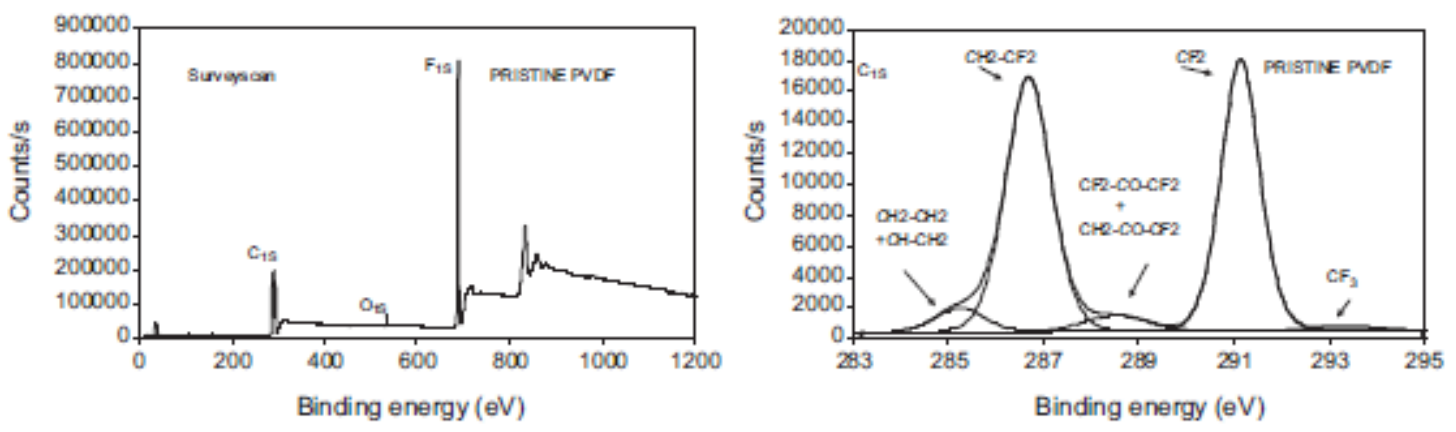

Fig. 2. XPS survey scan and C 1s core level spectra of pristine PVDF $\beta$. 


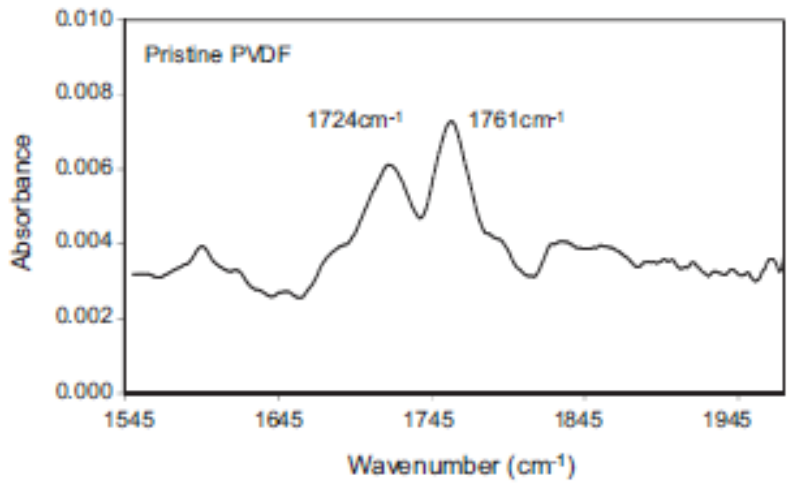

Fig. 3. Partial ATR FT-IR of pristine PVDF in the carbonyl absorption region. 


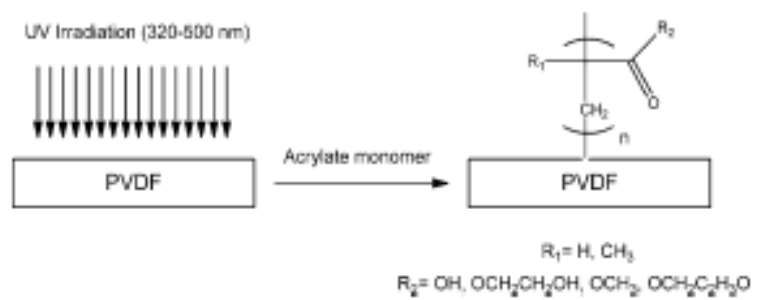

Fig. 4. Schematic process for surface modification of PVDF by UV-A irradiation. All steps were done under $\mathrm{N}_{2}$ atmosphere. 

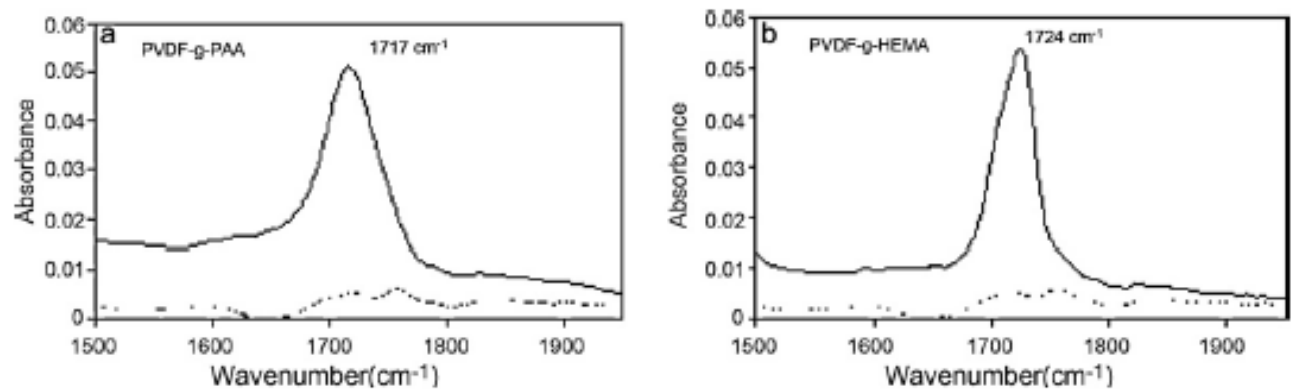

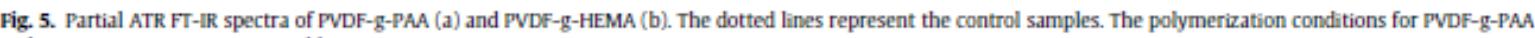
and PVDF-g-HEMA are given in Table 1. 

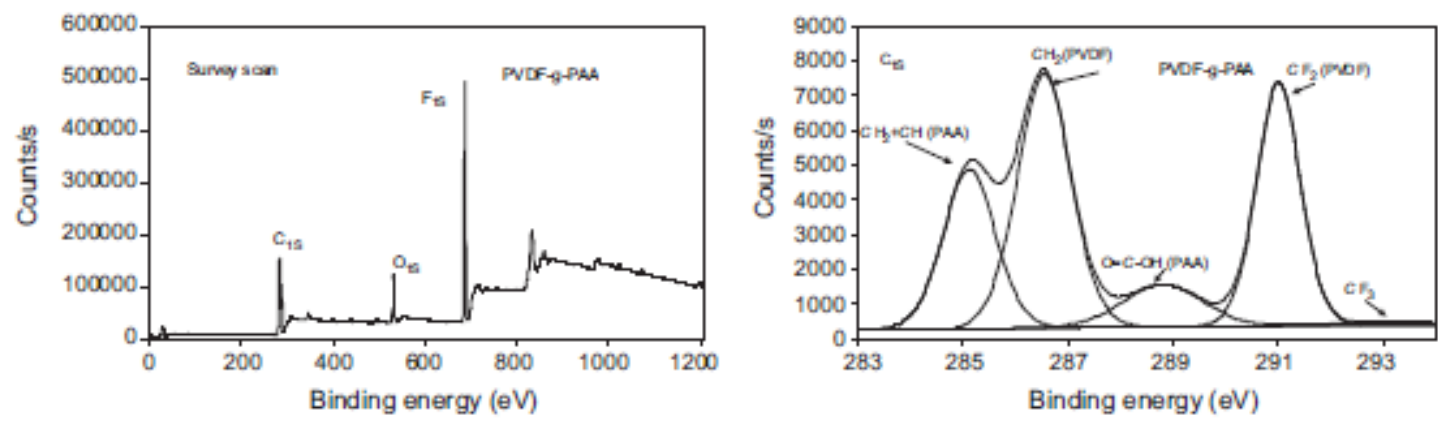

Fig. 6. XPS survey scan and $C$ is core level spectra of PVDF-PAA film. 


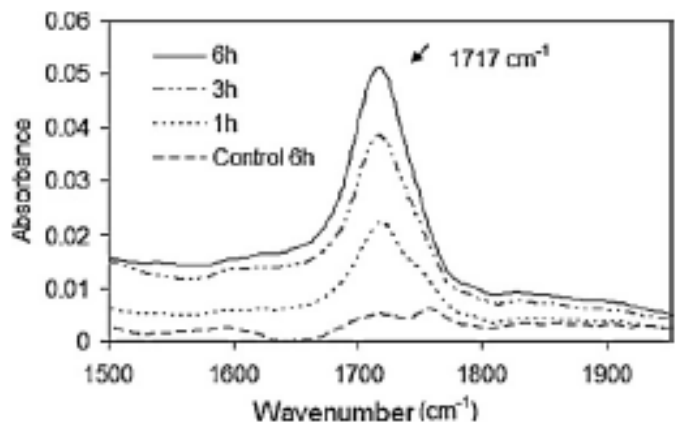

Fig. 7. Partial ATR FT-IR spectra of PVDF-PAA films obtained with different polymerization times. The other polymerization conditions are given in Table 1. 


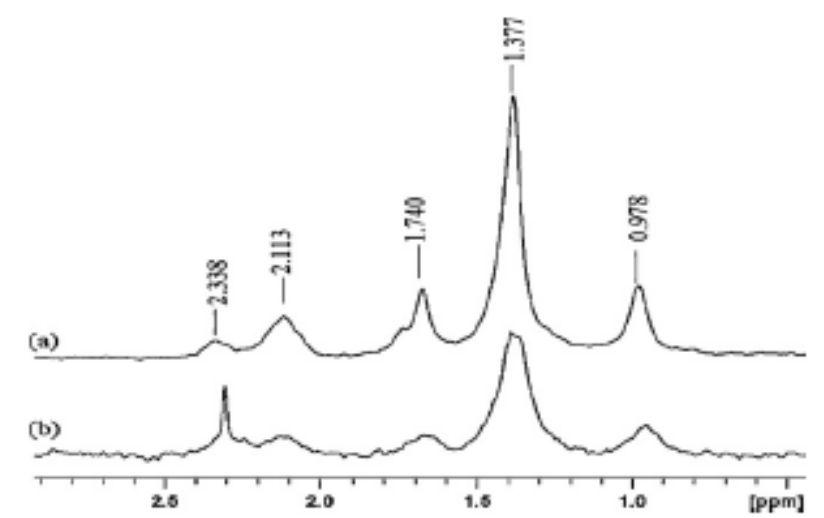

Fig. 8. Partial RMN HRMAS spectra of two PAA modified PVDF films. (a) Electron irradiated PVDF film follow by radiografting [10] and (b) PVDF film irradiated by UV $A$ and modified with acrylic acid. 


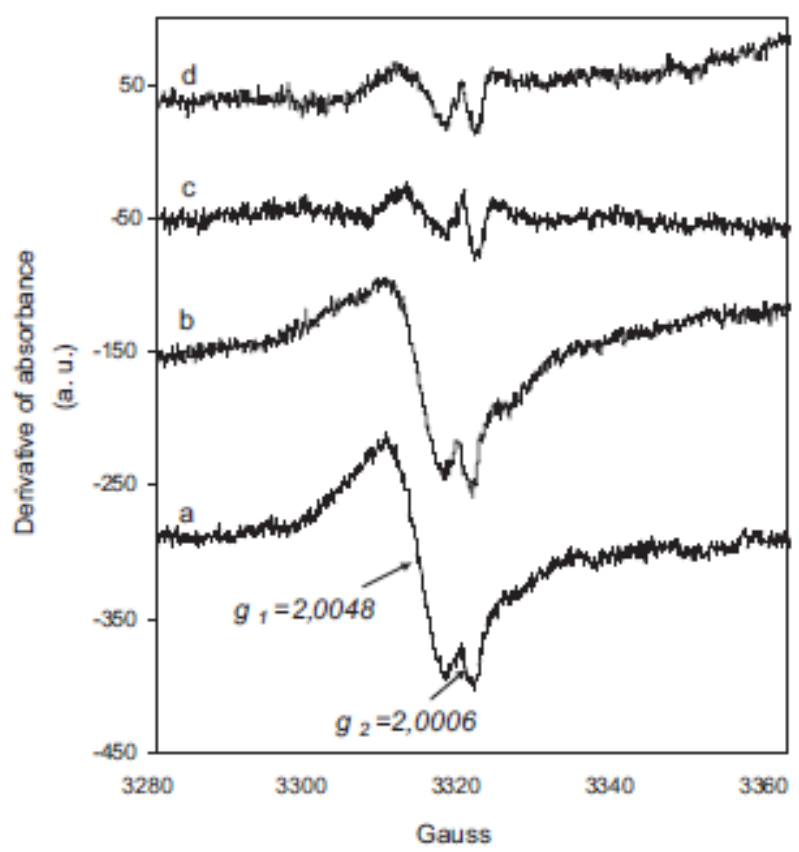

Fig. 9. EPR Spectra of PVDF film after (a) $15 \mathrm{~min}$, (b) 60 min of UV-A irradiation and 10 min air exposed and (c) after a relaxation time of 4.5 days and (d) pristine PVDF. 


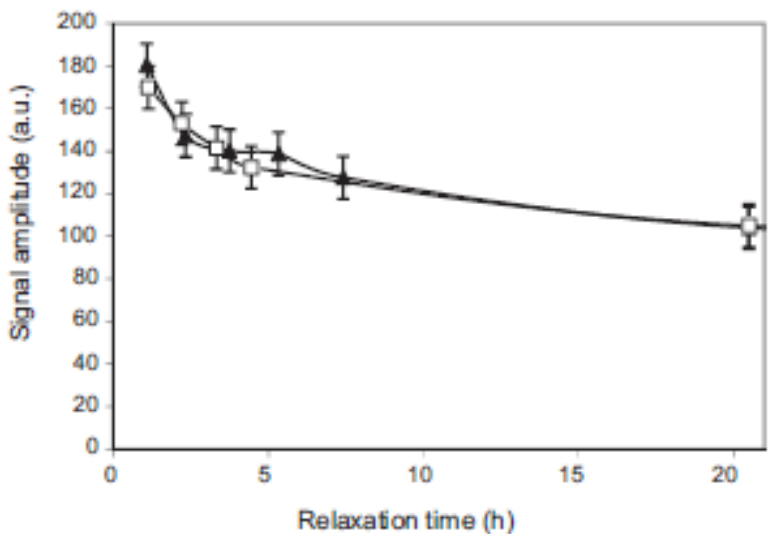

Fig. 10. Decrease of the amplitude EPR signal of UV-A irradiated and $10 \mathrm{~min}$ air exposed film ( $\mathbf{\Lambda}$ ) and UV-A irradiated film without air exposition ( $\square$ ). 


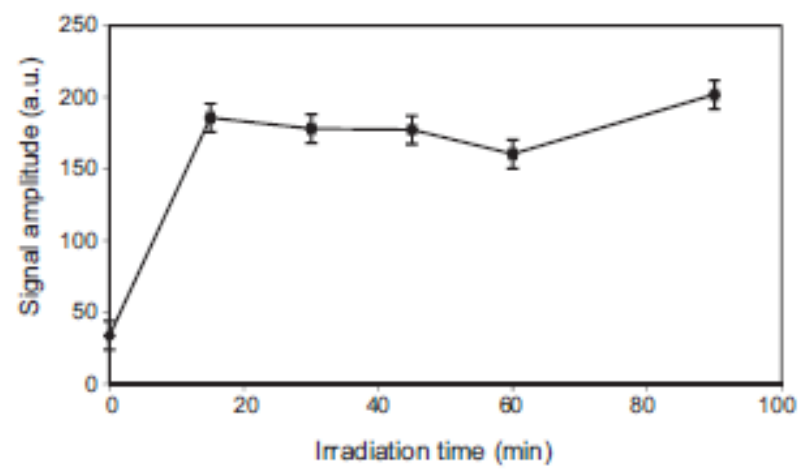

Fig. 11. EPR signal amplitude versus UV irradiation time. 


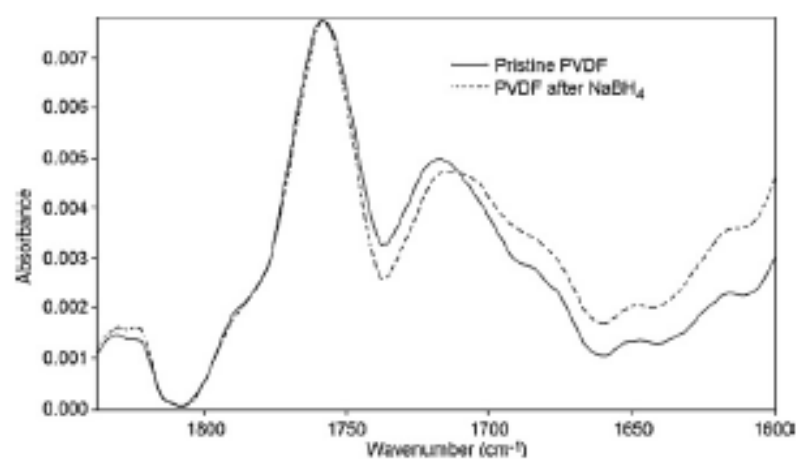

Fig. 12. Partial ATR FT-IR of PVDF in the carbonyl absorption region before and after reduction with aqueous $\mathrm{NaBH}_{4}$. 


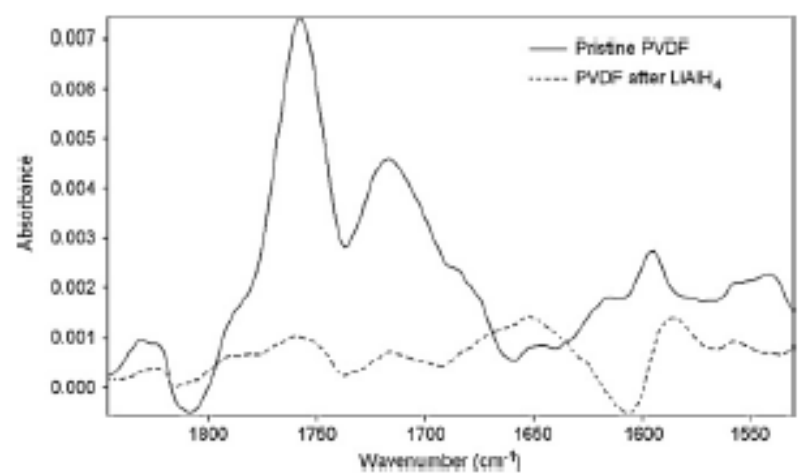

Fig. 13. Partial ATR FT-IR of PVDF in the carbonyl absorption region before and after reduction with a mixture of $\mathrm{LiAlH}_{4} / \mathrm{THF}$. 


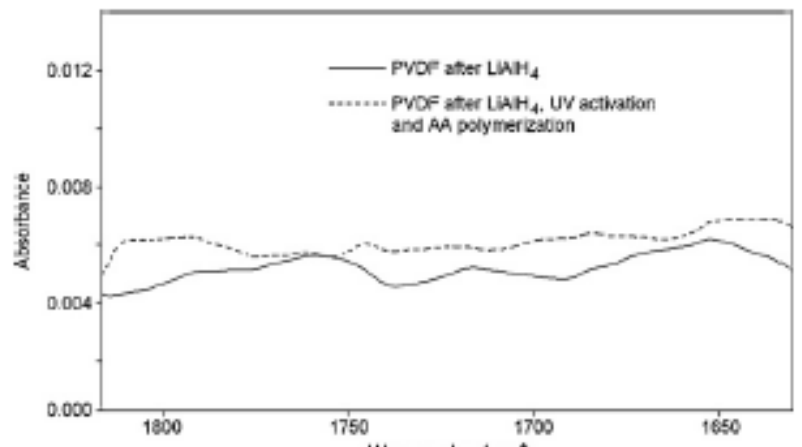

Fig. 14. Partial ATR FT-IR spectra of $\mathrm{LiAlH}_{4}$ reduced PVDF films after UV irradiation and AA polymerization procedures. 